\title{
Применение принципов МІМО для обнаружения неотражающих событий на рефлектограммах оптических волокон кабельных линий
}

\author{
Е.С. Зайщева ${ }^{1, *}$, А.В. Бурдин ${ }^{1,2,3}$, В.А. Бурдин ${ }^{1}$ \\ ${ }^{1}$ Поволжский государственный университет телекоммуникаций и информатики \\ ${ }^{2}$ АО "Государственный оптический институт им. С.И. Вавилова"

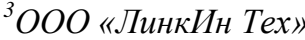 \\ *E-mail: zaytzewa@inbox.ru
}

DOI: 10.31868/RFL2020.181-182

Одной из проблем, с которой сталкиваются при обработке характеристик обратного Релеевского рассеяния оптических волокон участков кабельных линий, является обнаружение неотражающих событий - сварных соединений, нерегулярностей связанных с изгибами оптического кабеля и т.п. [1 - 6]. Задача поиска таких событий на рефлектограммах возникает при восстановлении документации линий, введенных в эксплуатацию, для обнаружения несанкционированного доступа, изгибов волокон в кабеле с недопустимо малым радиусом. Известен ряд способов обнаружения и локализации неотражающих нерегулярностей оптических волокон в кабеле [1-2, 7-14]. В частности, рассматривается применение для этих целей методов вейвлет-анализа [7, 12-13]. Применение указанных методов, с одной стороны, требует использования специального оборудования, а с другой стороны, их возможности, как, впрочем, и всех методов обработки сигналов, ограничены некоторыми пороговыми значениями отношения сигнал/помеха. В системах радиолокации удается существенно повысить вероятность и точность обнаружения целей при значительном снижении отношения сигнал/помеха за счет применения технологии MIMO (Multiple Input, Multiple Output) [15-17]. Данная технология предусматривает передачу пространственно-разнесенных зондирующих сигналов, прием эхо-сигналов и совместную обработку принятых сигналов. В [14] предложен вариант применения технологии МIMO для обнаружения и локализации неотражающих событий в оптических волокнах кабельной линии на элементарном кабельном участке.

События, отображающиеся на рефлектограммах оптических волокон в одном месте кабельной линии - сварные соединения в муфте, дополнительные потери в месте изгиба кабеля и т.П., - носят одинаковый характер, отличаясь только по степени изменения характеристики обратного рассеяния волокна. Это позволяет предположить, что совместная обработка характеристик обратного рассеяния группы оптических волокон кабельной линии позволит увеличить вероятность обнаружения на них неотражающих событий. В связи с этим и возникает вопрос об эффективности использования технологии МIMO для поиска и определения местоположения на рефлектограммах группы оптических волокон кабельной линии муфты оптического кабеля.

\section{Литература}

[1] Anderson D.R., Johnson L., Bell F.G. Troubleshooting optical-fiber networks. Understanding and using your optical time-domain reflectometer// Elsevier, London, 437 (2004)

[2] Листвин А.В., Листвин В.Н. Рефлектометрия оптических волокон // ЛЕСАРарт, Москва, 150 (2005)

[3] Understanding OTDRs// Anritsu, Issue 1, 56 (2011) 
[4] Peters J. Measurements in New Optical Cables. Pre-Construction and Post-Construction Measurements// Sterlite Technologies, Application Notes, (2012)

[5] Баяндин Д.В., Бочкова С.Д., Международный студенческий научный вестник 5, (2018).

[6] Евченко Е.В., Научно-практический электронный журнал Аллея Науки 8(24), 1-13 (2018)

[7] Манонина И.В., Т-Сотm, 10, 61-66 (2013)

[8] Lee, W., Myong, S. I., et al, Optics Express 22(1), 325(2014)

[9] Cen, M., Moeyaert, V., et al, Optics Express 22(8), (2014)

[10] Шубин В. В. Патент RU 2506701 C1, БИ №4, 9 (2014)

[11] Amaral G. C., Baldivieso A., et al, Journal of Lightwave Technology 35(10), 2025 (2017)

[12] Руднев Г.С., Шпилевой А.А., и др. Вестник Балтийского федерального университета им. И. Канта. Сер.: Физико-математические и технические науки 2, 72-80 (2018)

[13] Бурдин А.В., Бурдин В.А., и др. II Всероссийская конференция «Оптическая рефлектометрия - 2018». Сборник тезисов докладов, 55-57 (2018)

[14] Бурдин А. В., Дельмухаметов О. Р., и др. Патент RU 2698962C2, БИ №25, 25 (2019)

[15] Li J., Stoica P. MIMO Radar Signal Processing// Wiley-IEEE Press, 448 (2009)

[16] Черняк B.C., Успехи современной радиоэлектроники 2, 5-20 (2011)

[17] Жуков М.Н., Татарский Б. Г., Информаџионно-измерительные и управляющие системы 9(1), 36-45 (2011)

[18] Fernández M.P., Rossini L.A.B., et al, Optics Express 26(21), 27127-27140 (2018). 